\title{
Oil Price Shocks During the COVID-19 Pandemic: Evidence From United Kingdom Energy Stocks
}

\author{
Erhan Mugaloglu ${ }^{1}$ (D), Ali Yavuz Polat ${ }^{1}$, Hasan Tekin², Abdullah Dogan ${ }^{1}$ \\ 1 Economics, Abdullah Gul University, Turkey, ${ }^{2}$ Karabuk University, Turkey \\ Keywords: covid-19 pandemic, oil \& gas sector, svar, forecast error variance decomposition \\ https://doi.org/10.46557/001c.24253
}

\section{Energy RESEARCH LETTERS}

Vol. 2, Issue 1, 2021

We investigate the dynamic relationship between global oil prices, the stock market, and oil and gas stock (FTSE-OG) returns in the UK through a structural vector autoregressive (VAR) framework during the COVID-19 pandemic. The structural VAR results suggest that the impact of structural shocks related to the global oil price on FTSE-OG index returns becomes less important and loses its explanatory power during the pandemic. However, stock market shocks increase their explanatory power in the variations of FTSE-OG index returns.

\section{Introduction}

The effect of oil prices on macroeconomic indicators and stock markets is a popular topic in economics. Hamilton's (1983) seminal paper shows that most of the recessions in the US after World War II were caused by oil price shocks. Narayan \& Gupta (2015) prove the predictability power of oil prices on US stock returns for 150 years. Analyses conducted on the stock markets of various countries show that oil prices affect stock returns negatively (El-Sharif et al., 2005; Jones \& Kaul, 1996; Nandha \& Faff, 2008; Papapetrou, 2001; Sadorsky, 1999). In macroeconomic terms, an increase in oil prices is much more effective and determinative than a decrease (Hamilton, 2003). Kilian \& Park (2009) argue that this relationship holds only if there is a demand shock that is specific to the oil market and that increases in oil prices caused by a global economic boom or oil supply shocks do not show the same effect. Lee \& Zeng (2011) also challenge this phenomenon and show that the effect of oil price shocks on stock market returns is conditional on the general opinion of investors about the market's performance in the near future, that is, oil market shocks are not as profound when there is confidence in the markets.

Although the negative relationship between oil prices and stock market prices has been proven, it has also been observed that the stock prices of oil-producing companies increase with the oil prices. In addition, not all sectors are affected by oil price shocks in the same manner. Some sectors are slightly negatively affected, while others are not affected at all (Phan et al., 2015). There are also studies showing that oil price shocks may affect the stock markets of net oil-importing countries differently than those of oilexporters. The stock markets of oil-exporting countries react positively to oil price shocks, while such shocks have a negative impact on stock markets of oil-importers (Filis et al., 2011; Park \& Ratti, 2008; Wang et al., 2013). Silvapulle et al. (2017) examine the effect of oil prices on stock market returns in ten net oil-importing countries for a 16-year period. Their nonparametric panel data analyses show that the relationship is positive in the long run, but in times of economic and political crisis, it tends to be negative for short periods. Mollick \& Assefa (2013) examine the response of US stock markets to oil prices before and after the 2008 global economic crisis and find that the negative relationship seen before the 2018 crisis turned into a positive effect after the crisis.

The COVID-19 pandemic created disturbances both in oil prices and stock markets (Devpura \& Narayan, 2020; Iyke, 2020; Salisu et al., 2020). The relationship between oil prices and stock market prices is affected by the pandemic and declining oil prices decreased the stock market prices in the first months of the pandemic. Evidence from net oilimporting Asian countries suggests a positive relationship between oil prices and stock returns during the first five months (Prabheesh et al., 2020). However, in contrast, some studies indicate that the COVID-19 pandemic affected markets positively initially but later, there was a continuation of the negative relationship between prices of oil and stocks in this period (Liu et al., 2020).

In this study, we examine the relationship between Brent crude oil prices, the UK market index (FTSE-100), and the FTSE350-Oil \& Gas producers' (FTSE-OG) index. In order to eliminate robustness concerns due to the order of the variables, we conduct our analyses using a structural vector autoregressive (SVAR) model. We find that the FTSE-OG index and FTSE-100 are positively related and the FTSE-OG index becomes more volatile during the pandemic. Stock market shock can explain most of the variation in the FTSE-OG index returns throughout the observation period and the explanatory power increases during the pandemic compared to the pre-pandemic period. Global oil price shocks explain a relatively small part of the FTSE-OG index return variations. At the start of the outbreak, volatility is increased and the contemporaneous relation between FTSE-OG index returns and the global oil price becomes insignificant. 


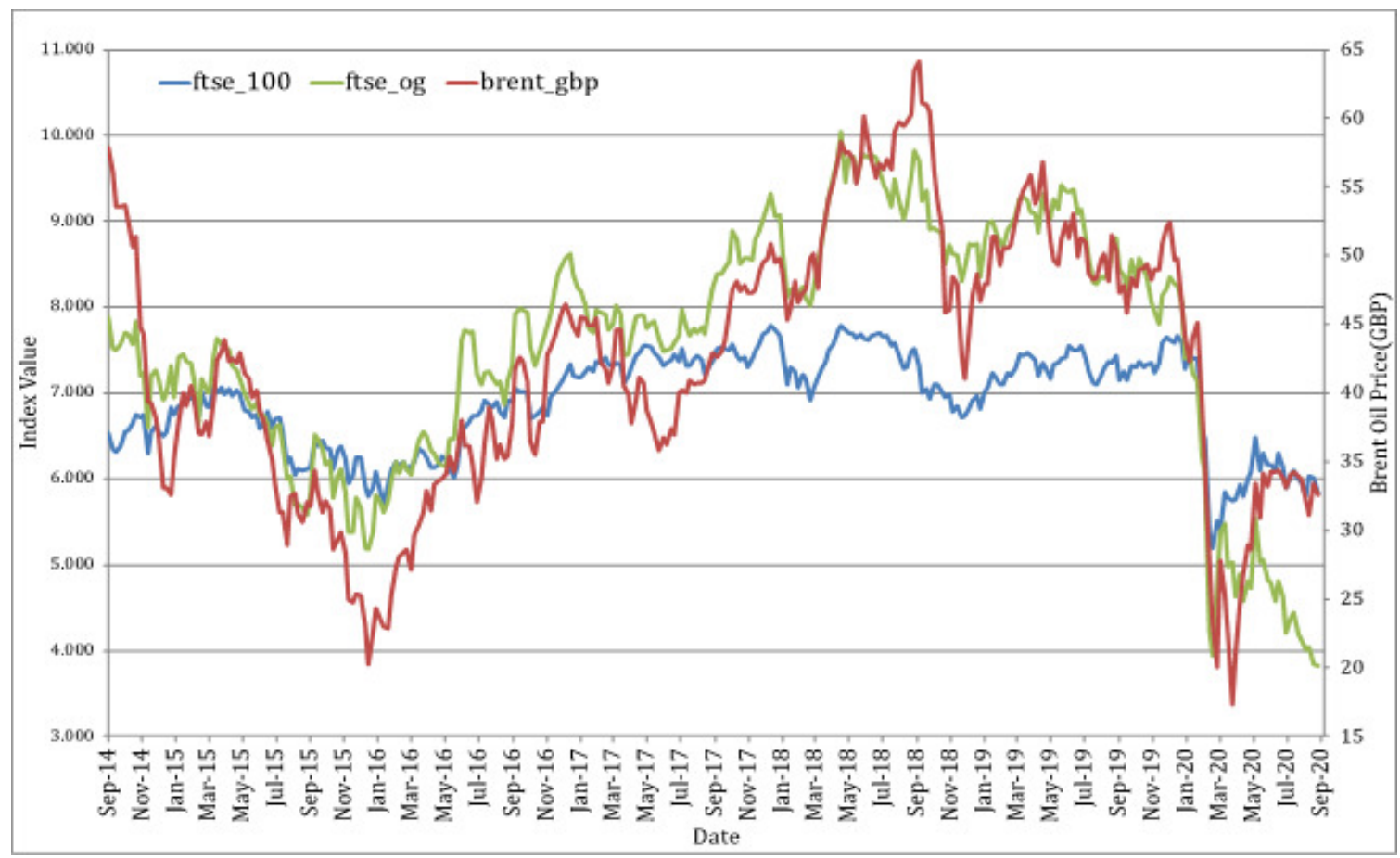

Figure 1. Time series plots of weekly market index (FTSE-100), oil price (Brent) and oil \& gas producers' index (FTSE-OG)

The figure shows time series plots of weekly market index, oil price and oil \& gas producers' index. FTSE-100 and FTSE-OG indices are depicted on the left axis and oil price (Brent) is depicted on the right axis. Brent is in terms of Great Britain Pound. The sample period is from September 28, 2014 to September 20, 2020.

\section{Data and Methodology}

\section{A. Data}

This study uses the FTSE-100 index as the UK's stock market proxy and Brent as the global oil price proxy. The FTSE-OG index, which includes five major oil and gas stocks traded on the London Stock Exchange, represents fossilfuel-producing firms' stock market performance in the UK. ${ }^{1}$ Figure 1 depicts the weekly evolution of the FTSE-100 and FTSE-OG indices with Brent oil prices from 09/2014 to 09/ 2020. According to Figure 1, there is a strong co-movement between the Brent price and the FTSE-OG index. However, this relation becomes insignificant just after the COVID-19 pandemic begins at which point all three variables fall sharply with the UK's first confirmed COVID-19 case in 02/ 2020. Therefore, this study splits data into pre-pandemic and pandemic periods to compare the dynamic interrelation between oil prices, market return, and fossil fuel stocks' performance.

The figure shows time series plots of weekly market index, oil price and oil \& gas producers' index. FTSE-100 and FTSE-OG indices are depicted on the left axis and oil price (Brent) is depicted on the right axis. Brent is in terms of Great Britain Pound. The sample period is from September 28, 2014 to September 20, 2020.

\section{B. Structural Vector Autoregression}

A SVAR model of Brent price, FTSE-100, and FTSE-OG can be used to identify structural shock through introducing restrictions on matrix $\mathrm{A}$, which indicates the contemporaneous relation of forecast errors, and matrix B for any correlation between structural shocks. The SVAR model can be written as:

$$
Z_{t}=A_{1} Z_{t-1}+\ldots+A_{p} Z_{t-p}+U_{t} \text { and } A U_{t}=B \varepsilon_{t}
$$

where $Z_{t}=[\text { brent, ftse, oilS }]^{\prime}$ is a vector of percentage change in the Brent oil price, FTSE-100 and FTSE-OG, respectively. $U_{t}$ and $\varepsilon_{t}$ denote forecast errors and structural shocks for each component of $Z_{t}$, respectively. The structural model with imposed restrictions in the $A$ and $B$ matrices can be written as:

$$
\begin{aligned}
& {\left[\begin{array}{ccc}
1 & 0 & 0 \\
0 & 1 & 0 \\
a_{31} & a_{32} & 1
\end{array}\right]\left[\begin{array}{l}
U^{\text {brent }} \\
U^{\text {ftse }} \\
U^{\text {oil }}
\end{array}\right]=} \\
& {\left[\begin{array}{ccc}
b_{11} & 0 & 0 \\
0 & b_{22} & 0 \\
0 & 0 & b_{33}
\end{array}\right]\left[\begin{array}{c}
\varepsilon^{\text {global-oil shock }} \\
\varepsilon^{\text {stock-market shock }} \\
\varepsilon^{\text {oil-sector shock }}
\end{array}\right]}
\end{aligned}
$$

1 The FTSE-OG index consists of BP, Cairn, Royal Dutch Shell (RDS) A and B, and Tullow Oil companies' stocks capitalizing approximately 61B, 847M, 132B, 132B, and 771M GBP in the LSE. While BP, RDSA, and RDSB stocks are indexed in FTSE-100, Cairn and Tullow Oil stocks are components of the FTSE-250 index. The website https:/www.investing.com/indices/oil-gas provides data and detailed information. 
Table 1. Estimated coefficients of the $A$ and $B$ matrices

\begin{tabular}{lccccc}
\hline Parameter & $a_{31}$ & $a_{32}$ & $b_{11}$ & $b_{22}$ & $b_{33}$ \\
\hline Pre-Covid & -0.2232 & -1.043 & 0.0443 & 0.01956 & 0.01744 \\
$28 / 09 / 2014$ & $(0.0234)$ & $(0.0530)$ & $(0.0018)$ & $(0.00082)$ & $(0.00073)$ \\
$01 / 03 / 2020$ & {$[-9.518]$} & {$[-19.679]$} & {$[23.753]$} & {$[24.456]$} & {$[23.744]$} \\
Post-Covid & 0.0959 & -2.262 & 0.04947 & 0.02109 & 0.01913 \\
08/03/2020 & $(0.0789)$ & $(0.1851)$ & $(0.0071)$ & $(0.0030)$ & $(0.00276)$ \\
$20 / 09 / 2020$ & {$[1.215]$} & {$[-7.458]$} & {$[7.067]$} & {$[6.928]$} & {$[6.9286]$} \\
\hline
\end{tabular}

This table shows the estimated coefficients of the $A$ and $B$ matrices. Standard errors and t-statistics are in parentheses and brackets, respectively

Table 2. Forecast error variance decomposition of FTSE-OG return

\begin{tabular}{lcccccc}
\hline & \multicolumn{3}{c}{$\begin{array}{c}\text { Panel A: Pre-pandemic period } \\
\text { 28/09/2014-01/03/2020 }\end{array}$} & \multicolumn{3}{c}{$\begin{array}{c}\text { Panel B: Pandemic period } \\
\text { 08/03/2020 - 20/09/2020 }\end{array}$} \\
\cline { 2 - 7 } Weeks & $\varepsilon^{\text {global-oil shock }}$ & $\varepsilon^{\text {stock-market shock }}$ & $\varepsilon^{\text {oil-sector shock }}$ & $\varepsilon^{\text {global-oil shock }}$ & $\varepsilon^{\text {stock-market shock }}$ & $\varepsilon^{\text {oil-sector shock }}$ \\
\hline 1 & $11.95 \%$ & $50.88 \%$ & $37.18 \%$ & $0.85 \%$ & $85.42 \%$ & $13.73 \%$ \\
2 & $11.99 \%$ & $50.76 \%$ & $37.25 \%$ & $7.10 \%$ & $66.55 \%$ & $26.35 \%$ \\
8 & $12.23 \%$ & $50.62 \%$ & $37.14 \%$ & $9.99 \%$ & $65.47 \%$ & $24.54 \%$ \\
16 & $12.32 \%$ & $50.57 \%$ & $37.10 \%$ & $9.91 \%$ & $65.27 \%$ & $24.82 \%$ \\
100 & $12.70 \%$ & $50.36 \%$ & $36.94 \%$ & $9.74 \%$ & $65.30 \%$ & $24.96 \%$ \\
\hline
\end{tabular}

This table has the forecast error variance decomposition results for the FTSE-OG return from SVAR model. Panel A has results covering the pre-pandemic sample period while Panel B has corresponding results for the pandemic period.

$$
\begin{gathered}
U^{\text {brent }}=b_{11} \varepsilon^{\text {global-oil shock }} \\
U^{\mathrm{ftse}}=b_{22} \varepsilon^{\text {stock-market shock }} \\
U^{\text {oilS }}=-a_{31} U^{\text {brent }}-a_{32} U^{\mathrm{ftse}}+b_{33} \varepsilon^{\text {oil-sector shock }}
\end{gathered}
$$

The imposed restrictions on matrix $A$ assume that Brent price and FTSE-100 satisfy weak exogeneity and thus are not contemporaneously related, while FTSE-OG reacts to the changes in Brent price and the FTSE-100 index in the same period (week). Besides, the diagonal structure of matrix $B$ assumes that the structural shocks are not correlated. Structural shocks related to forecast errors of Brent price, FTSE-100, and FTSE-OG are intuitively defined as the global oil shock, index shock, and oil and gas sector-related shocks, respectively.

\section{SVAR Results \\ A. Coefficients of $A$ and $B$ Matrices}

Table 1 presents the parameter estimation results of the coefficients of the $A$ and $B$ matrices. Regarding Table 1 and the signs of the parameters in Equation (3), $a_{32}$ suggests that the return on the FTSE-OG index is positively connected to the return on market return (FTSE-100). Furthermore, they vary almost equally during the pre-pandemic period but the return on the FTSE-OG index is more volatile than the market return during the pandemic. Secondly, $a_{31}$ implies that before the pandemic, the return on the FTSEOG index is positively associated with changes in the Brent price, but this contemporaneous relation becomes insignificantly negative at the start of the outbreak. Lastly, $b_{11}, b_{22}$, and $b_{33}$ reveal that the scale factors of structural shocks appear to be similar in both periods.

\section{B. Comparison of the Pre-Pandemic and Pandemic Periods: Evidence from Variance Decomposition}

Table 2 shows the contribution of global oil price, market index, and oil and gas sector-related structural shocks to variations in the FTSE-OG index return during the pre-pandemic and pandemic periods by employing variance decomposition. Before the COVID-19 pandemic (Panel A, on the left), the variation in the FTSE-OG index return is mostly (around 50\%) explained by market index shocks, then by oil and gas sector shocks (around 37\%), while the global oil price shock can explain only around $12 \%$ of the variation. Panel B presents forecast error variance decomposition for the pandemic period. The order of influence does not change but the contribution percentages change significantly during the pandemic compared to the case before the pandemic. During the pandemic period, the explanatory power of market index shock to the FTSE-OG index return variation increases from $50 \%$ to $65 \%$, and for the oil and gas sector shocks, the power decreases from $37 \%$ to $25 \%$. The explanatory power of global oil price shocks decreases from almost $13 \%$ to $10 \%$. These results imply the following: (i) stock market shocks contribute the largest part of the variation in the FTSE-OG index return; (ii) global oil price shocks can explain a relatively small part of the FTSE-OG return variation; and (iii) the explanatory power of structural shocks do not change dramatically in the short-term (2-8 weeks) and long-term (100 weeks) variations. 
Table 3. Variance-covariance matrices of the reduced form forecast errors

\begin{tabular}{|c|c|c|c|c|c|c|c|}
\hline \multicolumn{4}{|c|}{$\begin{array}{l}\text { Panel A: Pre-pandemic period } \\
\text { 28/09/2014-01/03/2020 }\end{array}$} & \multicolumn{4}{|c|}{$\begin{array}{l}\text { Panel B: Pandemic period } \\
08 / 03 / 2020-20 / 09 / 2020\end{array}$} \\
\hline & $U^{\text {brent }}$ & $U^{f t s e}$ & $U^{o i l S}$ & & $U^{\text {brent }}$ & $U^{f t s e}$ & $U^{o i l S}$ \\
\hline$U^{\text {brent }}$ & {$[0.196$} & & 7 & $U^{\text {brent }}$ & 0.244 & & 7 \\
\hline$U^{f t s e}$ & 0 & 0.038 & & $U^{f t s e}$ & 0 & 0.044 & \\
\hline$U^{o i l S}$ & 0.043 & 0.039 & 0.081 & $U^{o i l S}$ & -0.023 & 0.100 & 0.266 \\
\hline \multicolumn{2}{|c|}{$\operatorname{corr}\left(U^{\text {brent }}, U^{\text {oilS }}\right)$} & \multicolumn{2}{|r|}{0.345} & \multicolumn{4}{|c|}{-0.091} \\
\hline \multicolumn{2}{|l|}{$\operatorname{corr}\left(U^{f t s e}, U^{\text {oilS }}\right)$} & & 0.713 & \multicolumn{4}{|c|}{0.924} \\
\hline
\end{tabular}

This table has the variance-covariance matrices of the reduced form forecast errors. All values are 100 times the estimated variance-covariance matrices of residuals. Matrices are retrieved from the SVAR model. Panel A has results covering the pre-pandemic sample period while Panel B has corresponding results for the pandemic period.

\section{Comparison of the Pre-Pandemic and Pandemic Periods: Evidence from Variance- Covariance Matrices}

Table 3 shows the covariance matrices of reduced form forecast errors for both periods. First, during the pandemic, the variance of all variables increases compared to the prepandemic period. This is most probably due to the unprecedented uncertainty created by the pandemic. Second, the oil and gas sector stock returns' covariance with respect to the change in the Brent oil price decreases while its covariance with stock market returns increases. This result implies that the interrelation between FTSE-OG index returns and stock market returns increases during the pandemic.

\section{Conclusion}

This study investigates the dynamic relationship between global oil prices (Brent) the stock market (FTSE-100) and oil and gas stock (FTSE-OG) returns in the UK through imposing contemporaneous exogeneity restrictions in a SVAR framework and provides comparative estimations from the pre-pandemic and pandemic periods. The SVAR estimation results suggest that the impact of global oilprice-related structural shocks on FTSE-OG index returns becomes less important and loses its explanatory power after the outbreak emerges. In contrast, during the pandemic, stock market shocks increase their explanatory power in the variation of FTSE-OG index returns. According to our results, during the pandemic, global oil prices are not an informative tool for investors in the FTSE-OG index in the UK. Besides, during extreme uncertain times, such as the COVID-19 pandemic, the FTSE-OG index included investments that became riskier due to the rise in the contemporaneous impact of market index shocks. Energy stock investors should consider hedging against market index risk rather than only volatility in crude oil prices during the outbreak. 


\section{REFERENCES}

Devpura, N., \& Narayan, P. K. (2020). Hourly oil price volatility: The role of COVID-19. Energy Research Letters, 1(2), 13683. https://doi.org/10.46557/001c.13 $\underline{683}$

El-Sharif, I., Brown, D., Burton, B., Nixon, B., \& Russell, A. (2005). Evidence on the nature and extent of the relationship between oil prices and equity values in the UK. Energy Economics, 27(6), 819-830. $\underline{\mathrm{h}}$ ttps://doi.org/10.1016/j.eneco.2005.09.002

Filis, G., Degiannakis, S., \& Floros, C. (2011). Dynamic correlation between stock market and oil prices: The case of oil-importing and oil-exporting countries. International Review of Financial Analysis, 20(3), 152-164. https://doi.org/10.1016/i.irfa.2011.0 $\underline{2.014}$

Hamilton, J. D. (1983). Oil and the macroeconomy since World War II. Journal of Political Economy, 91(2), 228-248. https://doi.org/10.1086/261140

Hamilton, J. D. (2003). What is an oil shock? Journal of Econometrics, 113(2), 363-398. https://doi.org/10.101 6/s0304-4076(02)00207-5

Iyke, B. N. (2020). COVID-19: The reaction of US oil and gas producers to the pandemic. Energy Research Letters, 1(2), 13912. https://doi.org/10.46557/001c.13 $\underline{912}$

Jones, C. M., \& Kaul, G. (1996). Oil and the stock markets. The Journal of Finance, 51(2), 463-491. http s://doi.org/10.1111/i.1540-6261.1996.tb02691.x

Kilian, L., \& Park, C. (2009). The impact of oil price shocks on the U.S. stock market. International Economic Review, 50(4), 1267-1287. https://doi.org/1 0.1111/j.1468-2354.2009.00568.x

Lee, C.-C., \& Zeng, J.-H. (2011). The impact of oil price shocks on stock market activities: Asymmetric effect with quantile regression. Mathematics and Computers in Simulation, 81(9), 1910-1920. https://do i.org/10.1016/i.matcom.2011.03.004

Liu, L., Wang, E. Z., \& Lee, C. C. (2020). Impact of the COVID-19 pandemic on the crude oil and stock markets in the US: A time-varying analysis. Energy Research Letters, 1(1), 13154. https://doi.org/10.4655 7/001c.13154

Mollick, A. V., \& Assefa, T. A. (2013). U.S. stock returns and oil prices: The tale from daily data and the 2008-2009 financial crisis. Energy Economics, 36, 1-18. https://doi.org/10.1016/j.eneco.2012.11.021
Nandha, M., \& Faff, R. (2008). Does oil move equity prices? A global view. Energy Economics, 30(3), 986-997. https://doi.org/10.1016/i.eneco.2007.09.003

Narayan, P. K., \& Gupta, R. (2015). Has oil price predicted stock returns for over a century? Energy Economics, 48, 18-23. https://doi.org/10.1016/i.enec 0.2014.11.018

Papapetrou, E. (2001). Oil price shocks, stock market, economic activity and employment in Greece. Energy Economics, 23(5), 511-532. https://doi.org/10.1016/s0 140-9883(01)00078-0

Park, J., \& Ratti, R. A. (2008). Oil price shocks and stock markets in the U.S. and 13 European countries. Energy Economics, 30(5), 2587-2608. https://doi.org/1 $\underline{0.1016 / \text { i.eneco.2008.04.003 }}$

Phan, D. H. B., Sharma, S. S., \& Narayan, P. K. (2015). Oil price and stock returns of consumers and producers of crude oil. Journal of International Financial Markets, Institutions and Money, 34, 245-262. https://doi.org/10.1016/j.intfin.2014.11.010

Prabheesh, K. P., Padhan, R., \& Garg, B. (2020). COVID-19 and the oil price-stock market nexus: Evidence from net oil-importing countries. Energy Research Letters, 1(2), 13745. https://doi.org/10.4655 7/001c. 13745

Sadorsky, P. (1999). Oil price shocks and stock market activity. Energy Economics, 21(5), 449-469. https://do i.org/10.1016/s0140-9883(99)00020-1

Salisu, A. A., Ebuh, G. U., \& Usman, N. (2020). Revisiting oil-stock nexus during COVID-19 pandemic: Some preliminary results. International Review of Economics \& Finance, 69, 280-294. https://d oi.org/10.1016/j.iref.2020.06.023

Silvapulle, P., Smyth, R., Zhang, X., \& Fenech, J.-P. (2017). Nonparametric panel data model for crude oil and stock market prices in net oil importing countries. Energy Economics, 67, 255-267. https://do i.org/10.1016/i.eneco.2017.08.017

Wang, Y., Wu, C., \& Yang, L. (2013). Oil price shocks and stock market activities: Evidence from oilimporting and oil-exporting countries. Journal of Comparative Economics, 41(4), 1220-1239. https://do i.org/10.1016/j.jce.2012.12.004 